Fitzgerald, M. G., Malins, J. M., O'Sullivan, D. J., and Wall, M. (1961). Quart. F. Med., 30, 57.

Gross, M., Sexton, R. E., and Dorian, R. I. (1956). Bull. M. Hague

matern. Hosp., 9, 211 .
Harrison, T. R., et al. (1958). Principles of Internal Medicine, 3rd ed., p. 728. McGraw-Hill, Blackistan Division, New York.

Huggett, A. St. G., and Nixon, D. A. (1957). Lancet, 2, 368.

Johnstone, R. W., and Kellar, R. (1963). Text Book of Midwifery, 19th ed., p. 70. Black, London.

Joslin, E. P., Root, H. F., White, P., and Marble, A. (1952). Treatment of Diabetes Mellitus, 9th ed., p. 697 . Kimpton, London.

Keele, C. A., and Neil, E. (1965). Samson Wright's Applied Physiology, 11 th ed., p. 501 . Oxford Univ. Press, London.
Marks, V. (1959). Clin. chim. Acta, 4, 395

Payer (1899). Mschr. Geburtsh. Gynäk., 10, 559.

Peel, Sir John (1960). Brit. F. clin. Pract., 14, 837. edited by A. Claye and A. Bourne, p. 552 . Heinemann, London. Richardson, R., and Bitter, R. S. (1932). Amer. F. Obstet. Gynec., 24, 362 .

Thompson, R. H. S., and King, E. J. (1964). Biochemical Disorders in Human Disease, 2nd ed. Churchill, London.

Williams, E. C. P., and Wills, L. (1929). Quart. F. Med., 22, 493.

Williams, J. W. (1961). Obstetrics, 12th ed., p. 814. Appleton, New York.

Williams, J. T. (1925). Boston med. surg. 7., 192, 163.

\title{
Changes in Incidence and Aetiology of Bacteraemia Arising in Hospital Practice
}

\author{
P. J. WATT, $*$ M.B., M.R.C.P. ; O. A. OKUBADEJO, ${ }^{*} \dagger$ M.D., D.C.P.
}

Irit. med. 7., 1967, 1, 210-211

Since the introduction of antibiotic therapy many authors have recorded an increased incidence of bacteraemia arising in hospital practice. Emphasis has been placed on a marked rise in staphylococcal and Gram-negative bacteraemia, with a concomitant fall in potentially fatal infections due to the pneumococcus and Streptococcus pyogenes (Finland et al., 1959 ; Rogers, 1959 ; Faber et al., 1960). Factors other than antibiotics are involved in these changes; McHenry et al. (1962a) listed the ageing population, the widespread use of precipitating surgical and instrumental procedures, the prolongation of life in seriously ill patients with limited ability to resist infection, and the use of immune-suppressing drugs as factors in the increase of Gram-negative bacteraemia.

This report reviews the experience of bacteraemia at Hammersmith Hospital over the past eight years, and assesses some factors involved in an increasing incidence.

\section{Methods and Limitation of Study}

Bacteriological records for the period 1958 to 1965 were surveyed, and cases having potentially pathogenic organisms isolated from two or more consecutive blood cultures were accepted for further study. Solitary blood cultures were accepted as positive if a pure growth of a recognized pathogen was present in all bottles. Blood cultures were inoculated into two Castaneda bottles (Ruiz Castaneda, 1947) containing glucose broth with added "liquoid" and penicillinase, and into a bottle of cooked meat broth for the isolation of anaerobic organisms. Cultures were examined for a minimum period of 10 days.

Besides the limitations of a retrospective study some of our findings are biased by the numbers of patients referred to this centre with uraemia, blood dyscrasia, and malignant disease.

\section{Results}

During the period of this study there were 316 patients with positive blood cultures, Gram-negative rods accounting for 128 (40\%) and Staphylococcus aureus for $73(23 \%)$. Though the yearly number of hospital admissions rose from 12,100 in 1958 to 14,066 in 1965 , cases of bacteraemia increased dispropor\footnotetext{
* Department of Bacteriology, Royal Postgraduate Medical School, + Now Lecturer in Bacteriology, University College Hospital, Ibadan,
Nigeria.
}

tionately from 19 in 1958 to 65 in 1965 . Patients investigated for bacteraemia increased from 420 in 1958 to 660 in 1965 , while the average number of blood cultures taken from a suspected case rose from 2.0 to 3.7 .

\section{Gram-negative Infection}

Table I lists the annual number of positive blood cultures according to the causative organisms, and shows a progressive rise in all bacteraemia, with a sudden increase in the isolation of Gram-negative rods in 1960 . During this period no particular species of Gram-negative bacterium has become predominant, nor has the average age of the infected patients risen.

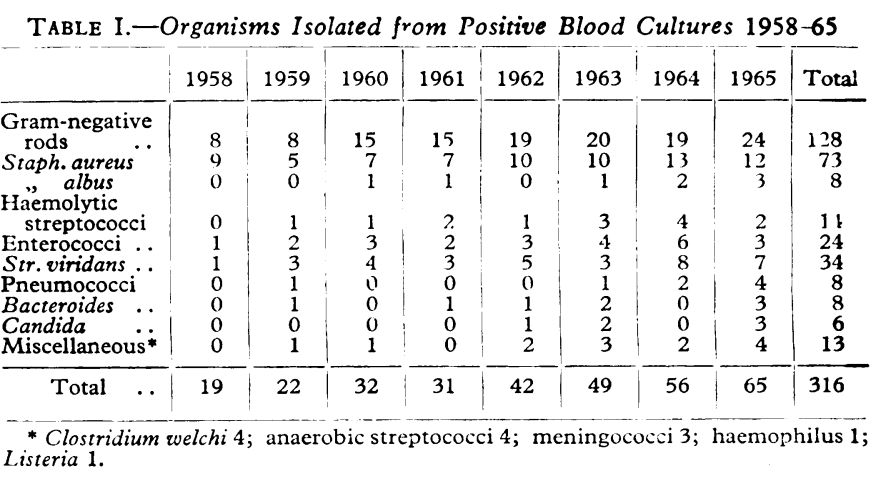

In 47 of the 128 cases of Gram-negative bacteraemis organisms were isolated on one occasion only, and clinical features did not suggest septicaemia. In these patients, with transient bacteraemia occurring as a complication of urinarytract manipulation and wound infections, no particular coliform was predominant.

Table II records the causative organisms in the 81 cases of Gram-negative septicaemia, together with the mortality rate. Pseudomonas pyocyanea was surprisingly common, accounting for 26 cases, with a mortality of $85 \%$. In two-thirds of these the blood stream was invaded from the urinary tract, most commonly complicating terminal uraemia, carcinoma of the bladder, or obstructive uropathy. The remaining cases were associated with wound infection or extensive skin destruction, generalized malignant disease, agranulocytosis, and in four patients followed Gram-positive septicaemia.

Of the remaining 54 cases of Gram-negative septicaemia the urinary tract was the portal of entry in 20,14 followed 
abdominal or pelvic surgery, and four complicated septic abortion. Of 16 cases where the portal of entry was undetected five were neonates, four had generalized malignancy, and the others Gram-positive septicaemia, agranulocytosis, or hepatic failure.

TABLE II.-Causative Organisms of Gram-negative Septicaemia

\begin{tabular}{|c|c|c|c|}
\hline Organism & & Patients & Mortality \\
\hline 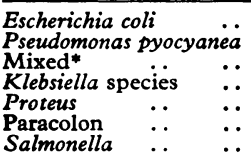 & $\begin{array}{l}\because \\
\because \\
\because \\
\because \\
. .\end{array}$ & $\begin{array}{r}30 \\
26 \\
10 \\
5 \\
3 \\
4 \\
3\end{array}$ & $\begin{array}{l}37 \% \\
85 \% \\
50 \% \\
60 \% \\
33 \% \\
50 \% \\
33 \%\end{array}$ \\
\hline
\end{tabular}

- Gram-negative rods 4; enterococci 3; bacteroides 2; Staph. aureus 1.

\section{Staphyloceal Infections}

The yearly rise in staphylococcal bacteraemia has been less marked than the overall incidence in positive blood cultures, and the pattern of infection remains constant.

Of 73 patients with staphylococcal bacteraemia 52 were infected in hospital, and one-third of these had previously received antibiotics to which the organism isolated was sensitive. In a quarter of hospital cases bacteraemia followed staphylococcal infection at the site of an intravenous infusion, or, in two recent cases, invasion of a Scribner arteriovenous shunt. Of 30 patients with bacteraemia complicating staphylococcal wound infections 10 were uraemic, 10 had malignant disease, and 10 underwent prolonged surgical procedures. The overall mortality of this group was $70 \%$, almost all the deaths occurring in patients with uraemia or carcinoma. Of the 14 patients in whom the staphylococcal infection was uncontrolled by adequate dosage of bactericidal antibiotics 11 were uraemic. The other seven deaths were attributable to complicating Gram-negative septicaemia and in one patient candidaemia. Four of the resmaining hospital infections were in babies with skin or umbilical sepsis, and the rest were infected from the urinary tract or peritoneal dialysis cannula.

During the same period there has been some increase in bacteraemia due to enterococci, anaerobic streptococci, and Bacteroides and Candida species, usually seen as a complication of wound infection or pelvic sepsis. Almost all the patients recently admitted with septicaemia due to pneumococci, meningococci, and haemolytic streptococci have had leucopenia or abnormality of the immunoglobulins.

\section{Discussion}

The incidence of bacteraemia in this hospital has risen from $1.65 / 1,000$ admissions in 1958 to $4.75 / 1,000$ admissions in 1965. Though Gram-negative bacteraemia increased from 0.62 to $1.7 / 1,000$ admissions, the incidence remains low compared with the recorded 5.7/1,000 admissions by Finland et al. (1959), 3.9/1,000 by McCabe and Jackson (1962), and 2.8/1,000 by Weil et al. (1964). This lower incidence may be due to the admission of fewer seriously ill patients, since Finland $e t$ al. noted an overall $7 \%$ hospital mortality rate compared with our $4 \%$.

Though it was not possible to assess the total operative and manipulative procedures performed, the admission of highrisk urogenital patients increased by $240 \%$, explaining much of the rise in Gram-negative bacteraemia. In the series of Gram-negative bacteraemia reported by Waisbren (1951) and Yow (1952) infections with Pseudomonas, Aerobacter, or Proteus species often followed antibiotic treatment. Of our 26 patients with pseudomonas septicaemia $88 \%$ received prior chemotherapy, compared with $23 \%$ for other Gram-negative rods. Though antibiotics select resistant infecting organisms, demonstration of an increased incidence would require matched controls. In this hospital the use of prophylactic antibiotics is strictly controlled, and there was no evidence implicating indiscriminate chemotherapy in the rising incidence of bacteraemia. McHenry et al. (1962b) showed that corticosteroids and cytotoxic drugs may provoke the onset of bacteraemia, but hospital use of these drugs has not obviously increased.

Despite routine polymyxin therapy the mortality of pseudomonas septicaemia was $85 \%$, compared with $45 \%$ for other Gram-negative rods. In McCabe and Jackson's (1962) study of Gram-negative bacteraemia the mortality rate was independent of the causative organism, but $66 \%$ of patients with ultimately fatal disease died of bacteraemia, compared with $11 \%$ with non-fatal disease. Though 20 of our patients with pseudomonas septicaemia had ultimately fatal disease, we agree with Forkner et al. (1958), who found a higher mortality for pseudomonas than for coliform septicaemia in leukaemic patients.

Many authors, including Hassall and Rountree (1959) and Faber et al. (1960), have observed marked increases in staphylococcal bacteraemia. In this hospital staphylococcal bacteraemia has increased from $0.5 / 1,000$ admissions in 1958 to $0.86 / 1,000$ in 1965 ; the increase was confined to hospital-infected cases. Despite constant effort to reduce staphylococcal cross-infection, 34 of the 53 infections arising in hospital were caused by staphylococci of phage types associated with hospital epidemics and resistant to two or more antibiotics.

Hassall and Rountree (1959) implicated the indwelling polyethylene catheter as a portal of entry in staphylococcal bacteraemia, but despite a marked reduction in prolonged caval infusions there was no decrease in cases associated with intravenous therapy. Moran et al. (1965) found $14 \%$ of venous cutdowns were complicated by bacteraemia, and felt that percutaneously inserted plastic catheters caused as many septic complications. Bacteraemia did not occur in patients receiving a local antibiotic cream.

Death from staphylococcal bacteraemia was confined to patients with severe underlying disease, often as a terminal event, but some uraemic patients had potentially reversible disease.

\section{Summary}

Survey of bacteriological records at Hammersmith Hospital showed that patients with bacteraemia had increased from 19 in 1958 to 65 in 1965. Much of the increase was due to miscellaneous infections, but Gram-negative bacteraemia increased from 0.62 to $1.7 / 1,000$ admissions and staphylococcal from 0.5 to 0.86 .

This increase was not explained by indiscriminate chemotherapy or more widespread use of immunosuppressive drugs ; but a disproportionate rise in urogenital cases accounts for much of the rise in Gram-negative bacteraemia.

Hospital bacteraemia was largely confined to the very ill patient, and the mortality parallels the severity of the underlying disease.

We are glad to acknowledge the help of the late Professor Mary Barber in initiating this study.

\section{REFERENCES}

Faber, V., Jessen, O., Rosendal, K., and Eriksen, K. R. (1960). Brit.

Finland, M., Jones, W. F., jun., and Barnes, M. W. (1959). F. Amer. med. Ass., 170, 2188 .

Forkner, C. E., Frei, E., Edgcomb, J. H., and Utz, J. P. (1958). Amer. f. Med., 25, 877 .

Hassall, J. E., and Rountree, P. M. (1959). Lancet, 1, 213

McCabe, W. R., and Jackson, G. G. (1962). Arch. intern. Med., 110, 847. McHenry, M. C., Martin, W. J., and Wellman, W. E. (1962a). Ann. intern. Med., 56, 207.

Hargraves, M. M., and Baggenstoss, A. H. (1962b). Mayo Clin. Proc., 37, 43.

Moran, J. M., Atwood, R. P., and Rowe, M. I. (1965). New Engl. F. Med., 272, 554.

Rogers, D. E. (1959). Ibid., 261, 677.

Ruiz Castaneda, M. (1947). Proc. Soc. exp. Biol. (N.Y.), 64, 114

Waisbren, B. A. (1951). Arch. intern. Med., 88, 467. Weil, M. H., Shubin, H., and Biddle, M. (1964). Ann. intern. Med., 60,

Yow, E. M. (1952). F. Amer. med. Ass., 149, 1184. 